\title{
Association between body mass index and spatial gait parameters in primary school children
}

\author{
Mohamed Rageh Abd Elazeem ${ }^{1,2^{*}}$, Amira Mohamed Eltohamy ${ }^{2}$ and Mostafa Soliman Ali ${ }^{2}$
}

\begin{abstract}
Background: Increasing BMI is associated with increased risk of mortality, cardiovascular disease, and some cancers whereas a lower BMI is associated with an increased risk of mortality, postsurgical complications, infection, and length of hospital stay as a result. Locomotion is a unique feature of the animal kingdom. It allows individuals to meet others, to find better food and a better climate, to pursue prey, or to escape impending danger. The aim of the current study was to determine the correlation between body mass index (BMI) and spatial gait parameters in primary school children.

Results: A total of 320 healthy children from primary schools were enrolled. The participants comprised 185 boys and 135 girls with a mean age of $10.05 \pm 0.95$ years, mean weight of $38.49 \pm 12.2 \mathrm{~kg}$, a mean height of $139.25 \pm$ $10.12 \mathrm{~cm}$, and a mean BMI of $19.35 \pm 4.55 \mathrm{~kg} / \mathrm{m}^{2}$. BMI was evaluated by the KINLEE Electronic Personal Scale with Height Measurement and CDC charts for boys and girls and equation of BMI. Spatial gait parameters were evaluated by a pediatric run-based anaerobic sprint test with an Omron pedometer to assess step and stride length.

Statistical analysis was performed by Pearson's correlation coefficient to study the relationship between variables. A correlation was performed between the variables, and the coefficient of determination was calculated. The significance level was set at $5 \%$ for all analyses. There was no significant relationship between $\mathrm{BMI}$ and spatial gait parameters (step length and stride length) $(r=0.008, p=0.88$ and $r=0.02, p=0.7$, respectively).

Conclusion: According to the results, we concluded that there was no significant relationship between BMI and the measured gait parameters (step length and stride length).
\end{abstract}

Keywords: Body mass index, Gait, Gait parameters, Pedometer

\section{Background}

Body mass index (BMI) indicates the association between weight and height and is mainly used to provide an assessment of healthy, malnourished, or obese individuals [1]. A high BMI indicates greater body fat; BMI cannot directly detect the amount of body fat but correlates with direct measurements of fat as skinfold thickness, bioelectrical impedance, densitometry, and dualenergy X-ray absorptiometry (DXA) [2]. Overall, BMI is

\footnotetext{
* Correspondence: mohamedrageh915@gmail.com

${ }^{1}$ Shoubra Elkheima, Egypt

${ }^{2}$ Faculty of Physical Therapy, Cairo University, Cairo, Egypt
}

an economical and easy way to screen categories of weight and to assess body fat that may lead to health problems [3]. BMI is age- and sex-related, for children and teenagers. Children with high body fat can suffer from weight-related diseases and other health problems, while underweight children may be at risk of concerns regarding their wellbeing [4]. BMI is the most effective anthropometric method to estimate a healthy body weight based on a child's height [4]. BMI is related with mortality and morbidity rates in adults, while associations between BMI or alterations in BMI and high blood pressure, increased fat in arteries (atherosclerosis),

\section{Springer Open}

(c) The Author(s). 2021 Open Access This article is licensed under a Creative Commons Attribution 4.0 International License, which permits use, sharing, adaptation, distribution and reproduction in any medium or format, as long as you give appropriate credit to the original author(s) and the source, provide a link to the Creative Commons licence, and indicate if changes were made. The images or other third party material in this article are included in the article's Creative Commons licence, unless indicated otherwise in a credit line to the material. If material is not included in the article's Creative Commons licence and your intended use is not permitted by statutory regulation or exceeds the permitted use, you will need to obtain permission directly from the copyright holder. To view a copy of this licence, visit http://creativecommons.org/licenses/by/4.0/. 
adverse lipoprotein profiles, and non-insulin-dependent diabetes mellitus can be demonstrated in children and adolescents [5]. BMI can be interpreted for children and teens in different way, but can be calculated using the same method as that used for adults, as there is a relationship between the amount of body fat and age and a difference in the accumulation of fat between both sexes. The CDC growth chart can be used to establish these sex- and age-related differences, and shows the BMI as a percentile ranking from 2 to 19 years [6]. Klein et al. classified BMI percentiles into five categories as follows: underweight, < 5 percentile; normal weight, 5-84 percentile; overweight, 85-94 percentile; obese $>95$ percentile; and severe obesity, $>99$ percentile [7].

Gait is the mechanism of human ambulation or locomotion of all body parts. Gait is an essential indicator of human motor development and can affect more complicated tasks, such as running and jumping [8]. Gait depends on adequate balance and sufficient force during child development [9]. Gait plays an essential role in daily activities, and may be exaggerated by internal or external influences, such as becoming obese or aging [9]. The mean age for onset of independent walking ranges from 11 to 14.5 months [10, 11]. EMG activation during gait and a mature pattern of muscle recruitment for healthy children during gait is completed by the age of 6-8 years [12]. The gait cycle is defined as a repeated pattern of steps and strides. The step length is defined as the length from the heel of the previous foot fall to heel of the current opposing foot fall in parallel to the line of progression of the body. Stride length is the distance measured parallel to the line of progression, between the posterior heel points of two consecutive footprints of the foot in question or the distance covered when you take two steps. Step width is the medio-lateral distance between the two feet [13]. The outcome of this study will likely be beneficial for the planning treatment programs. Moreover, our findings will benefit children given that the development of normal motor skills has a direct effect on cognitive development. Also, the fundings can help in planning preschool stage to control weight during preschool period and primary stage as preventive means or treatment means in obesity administration.

\section{Methods}

\section{Design}

This cross-sectional study was approved by the Ethical Committee of Faculty of Physical Therapy, Egypt, and was performed in accordance with the Declaration of Helsinki of 1964 and its later amendments. The parents of all participating children signed consent forms for their participation.

\section{Participants}

A total of 320 healthy children (185 boys and 135 girls, aged 9-11 years old) were selected from primary school in north Giza to participate in this study. All children were included in the analysis as they all met the inclusion criteria of being able to understand instruction and cooperate during assessment. The exclusion criteria were as follows: (1) children with cardiopulmonary disorders; (2) children with orthopedic problems; (3) athletic children; (4) children with auditory and visual problems; and (5) children with intellectual disorders.

\section{Procedure}

\section{Evaluation of BMI}

Children's height and weight were measured using the KINLEE Electronic Personal Scale with Height Measurement after removing shoes and their clothes were light school uniform, and the results were recorded on BMI tables provided by CDC chart for boys and girls percentiles. The BMI was subsequently calculated using the BMI equation:

$$
\left(\mathrm{BMI}=\frac{\text { weight }(\mathrm{kg})}{\text { heightsquared }\left(\mathrm{m}^{2}\right)}\right) .
$$

\section{Evaluation of gait parameters}

The pediatric run-based anerobic sprint test and Omron Alvita ultimate pedometer (model: hj-325) were used to assess step length and stride length.

\section{Pedometer}

A pedometer is portable electronic or electromechanical device that counts each step taken by a person through the determination of hand or hip motion by automatic software. A pedometer can be worn on a belt to record how many steps are walked by the wearer and how a child's step varies.

\section{Pediatric run-based anerobic sprint test}

The $15-\mathrm{m}$ sprinting trace was obvious by two lines recorded on the floor. Cones were placed at the end of each of the lines, and the child was instructed to complete six $15-\mathrm{m}$ sprints at maximum speed until they have crossed the end line. The time of each sprint was manually timed to the hundredth of a second. A 10-s rest was necessary before starting the second sprint to sufficiently prepare the child. The children were verbally motivated to sprint as fast as possible to achieve maximal effort. For the first sprint, the countdown was in the form of "ready, 3, 2, 1 , go." For the remaining five sprints, the countdown was in the form of 6 to 1 , then "go." 


\section{Procedure for step and stride length assessment}

During the application of Pediatric RAST, each child was instructed to wear the Omron pedometer around their waist. The step length was obtained by dividing the total distance from six trials $(90 \mathrm{~m}$ in total) by the number of steps counted by the pedometer. The stride length was obtained by dividing the number of steps by 2 to get the number of strides, then dividing the total distance of six trials by the numbers of strides.

\section{Data analysis}

Statistical analysis was performed using Statistical Package for Social Sciences program version 25. Descriptive results were generated by calculating the means and standard deviations. For the statistical data analysis, the scores of BMI were calculated using the BMI equation outlined above, step and stride length were calculated by dividing the total distance of the six trials by the number of steps to obtain the step length, and the total distance of six trials divided by the number of strides to obtain the stride length using a pedometer.

The Shapiro-Wilk test confirmed the normality in the data distribution $(p \geq 0.05)$. Pearson's correlation coefficient was used to study the relationship between variables. A correlation was performed between the variables, and the coefficient of determination was calculated. The significance level was set at $5 \%$ for all analyses.

\section{Results}

The mean \pm SD age, weight, height, and BMI of the 320 children in the study were $10.05 \pm 0.95$ years, $38.49 \pm$ $12.2 \mathrm{~kg}, 139.25 \pm 10.12 \mathrm{~cm}$, and $19.53 \pm 4.55 \mathrm{~kg} / \mathrm{m}^{2}$, respectively, as shown in Table 1 .

\section{Descriptive statistics of the gait parameters of the children}

The mean \pm SD step length of the children was $1.14 \pm$ $0.15 \mathrm{~m}$, with a minimum value of $0.7 \mathrm{~m}$ and a maximum value of $1.5 \mathrm{~m}$, as shown in Table 1 . The mean $\pm \mathrm{SD}$

Table 1 Descriptive characteristics of the children

\begin{tabular}{llll}
\hline & $\bar{X} \pm$ SD & Maximum & Minimum \\
\hline Age (years) & $10.05 \pm 0.95$ & 11.9 & 8.5 \\
Weight $(\mathbf{k g})$ & $38.49 \pm 12.2$ & 82.5 & 18.75 \\
Height $(\mathbf{c m})$ & $139.25 \pm 10.12$ & 168 & 110 \\
BMI (kg/m $\left.{ }^{\mathbf{2}}\right)$ & $19.53 \pm 4.55$ & 37 & 12.4 \\
& Sex distribution & & \\
& Girls & Boys & \\
No. (\%) & $135(42 \%)$ & $185(58 \%)$ & \\
Total & $320(100 \%)$ & & \\
\hline X & & &
\end{tabular}

$\overline{\mathrm{X}}$ mean, SD standard deviation stride length of the children was $2.3 \pm 0.28 \mathrm{~m}$, with a minimum value of $1.5 \mathrm{~m}$ and a maximum value of 3.2 $\mathrm{m}$, as shown in Table 2 .

\section{Relationship between BMI and step and stride length of the children}

According to the results $(r=0.008, p=0.88)$ and $(r=$ $0.02, p=0.7)$ of step length and stride length respectively in relation to BMI, there was non-significant relation between BMI and step and stride length in the current study (Table 3, Figs. 1 and 2).

\section{Discussion}

The aim of the current research was to study the relationship between BMI and gait parameters (step length and stride length). According to our results, there was no relationship between BMI and step length, as the Pearson correlation was 0.008 and the $p$ value was 0.88 . Moreover, there was no relationship between BMI and stride length, as the Pearson correlation was 0.02 and the $p$ value was 0.7 . These results are in agreement with those of Pathare et al. (2013) [14], who found no significant differences in step length and stride length when comparing physical performance measures among young healthy weight, overweight, and obese children. The current results are also in agreement with those of Cimolin et al. (2015) [15], who studied the gait pattern in lean and obese adolescents, and found no significant differences in step length and stride length between normal and obese adolescents. The results of the present study are also in accordance with those of Cimolin et al. (2019) [16], who studied gait symmetry in normal weight, underweight, and obese children aged 7-14 years and found no significant differences in step length and stride length. Moreover, Rosso et al. (2019) [17] found no significant differences between spatial parameters of gait in normal weight and overweight subjects during a defined walking speed.

Additionally, no gait alterations were found as a result of speed, and no differences were observed between normal weight, overweight, and obese children with regard to step and stride length.

The current study results agree with those of Rezaei et al. (2018) [18] who studied thin, normal, and overweight boys aged 7-9 years using 3D motion analysis and found no significant difference between step length

Table 2 Descriptive characteristics of the gait parameters of the children

\begin{tabular}{llll}
\hline Gait parameters & $\mathbf{X} \pm \mathbf{S D}$ & Minimum & Maximum \\
\hline Step length & $1.14 \pm 0.15$ & 0.7 & 1.5 \\
Stride length & $2.3 \pm 0.28$ & 1.5 & 3.2 \\
\hline
\end{tabular}


Table 3 Correlation between BMI and step length of the children

\begin{tabular}{lllll}
\hline & & $\boldsymbol{r}$ value & $\boldsymbol{p}$ value & Sig \\
\hline BMI $\left(\mathbf{k g} / \mathbf{m}^{2}\right)$ & Step length & 0.008 & 0.88 & $\mathrm{NS}$ \\
BMI $\left(\mathbf{k g} / \mathbf{m}^{2}\right)$ & Stride length & 0.02 & 0.7 & $\mathrm{NS}$ \\
\hline
\end{tabular}

$r$ value Pearson correlation coefficient, $p$ value probability value, NS non-significant

and stride length in normal, thin, and overweight children.

These results are in accordance with those of Milanese et al. (2010) [19] who evaluated motor abilities and anthropometric parameters in normal children from both sexes with age ranged from 6 to 12 years, they assessed standard anthropometry (BMI, waist circumference, waist-to-hip ratio, the sum of five skinfolds) and motor fitness tests (standing long jump and 30-m dash), they found that the BMI does not correlate with run and other spatial gait parameters (step and stride length).

However, these results disagree with those of Hung et al. (2013) [20], who investigated the effect of dual-task constraints on the whole-body organization during ambulation in normal, overweight, and obese children. They demonstrated that the overweight and obese children had a shorter normalized step and stride lengths than the control children, and decreased their normalized step and stride lengths under the dual-task condition compared with the normal-walking condition.

The present study results contradict those of Heneidy (2012) [21], who found significant differences in the measured variables between different categories of weight abnormalities on gait parameters in children aged 12-14 years, as measured using a Biodex gait trainer treadmill. The obese children could walk a shorter distance, with a significantly slower speed, shorter steps, and a decrease in the average step cycle compared with normal-weight children. Moreover, the results of the underweight children were better than those of the other groups but were still less than those of the normalweight group.

These results disagree with the study by Dufek et al. (2012) [22], which demonstrated significant differences in step and stride length of normal weight, overweight, and obese adolescents (both sexes, aged 12-17 years) using an instrumented walkway where all participants walked at two speeds (preferred, fast).

Our results also disagree with those of Gouws et al. (2010) [23], who studied the influence of child obesity on gait biomechanics. They studied the relationship between BMI and spatial-temporal parameters of gait on overweight, obese, and normal weight school-aged children (12-14 years) at two different walking speeds (slow and fast speed). Their results showed a negative relationship between BMI and step and stride lengths, in that obese and overweight children showed shorter step and stride lengths than non-obese children.

Furthermore, our results also disagree with those of Roles et al. (2016) [24], who studied differences in running mechanics between overweight/obese and healthy weight children. Children between 8 and 12 years of age were enrolled, all of whom wore standardized footwear (Nike Pegasus) to control for the effect of footwear on running mechanics. Spatialtemporal parameters were measured, and the researchers found that the overweight/obese group displayed significantly shorter step lengths during running than the healthy control group. Thus, they concluded that there is a negative relationship between BMI and step length and stride length.

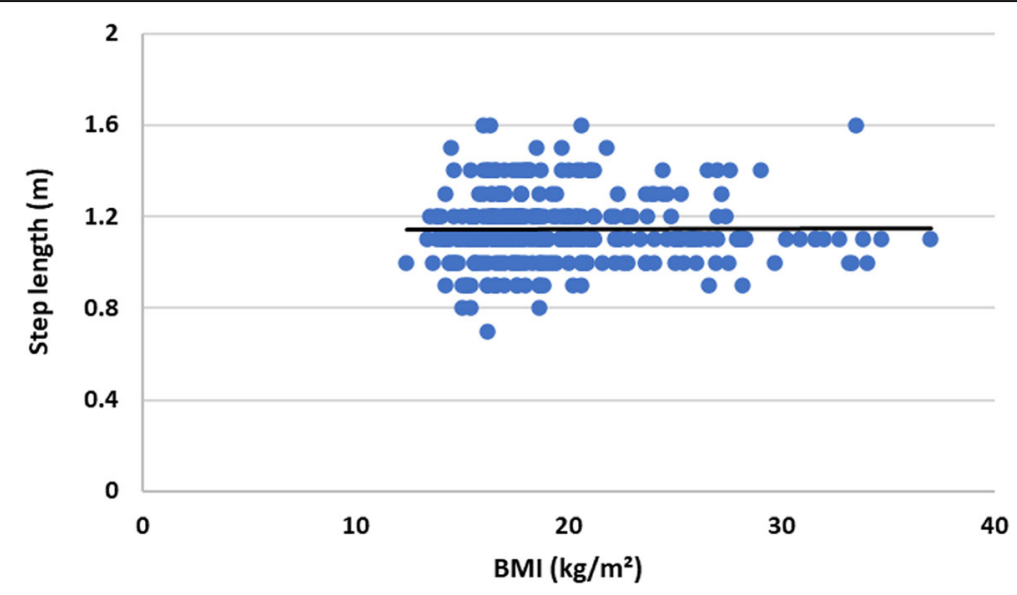

Fig. 1 Correlation between BMI and step length of the children 


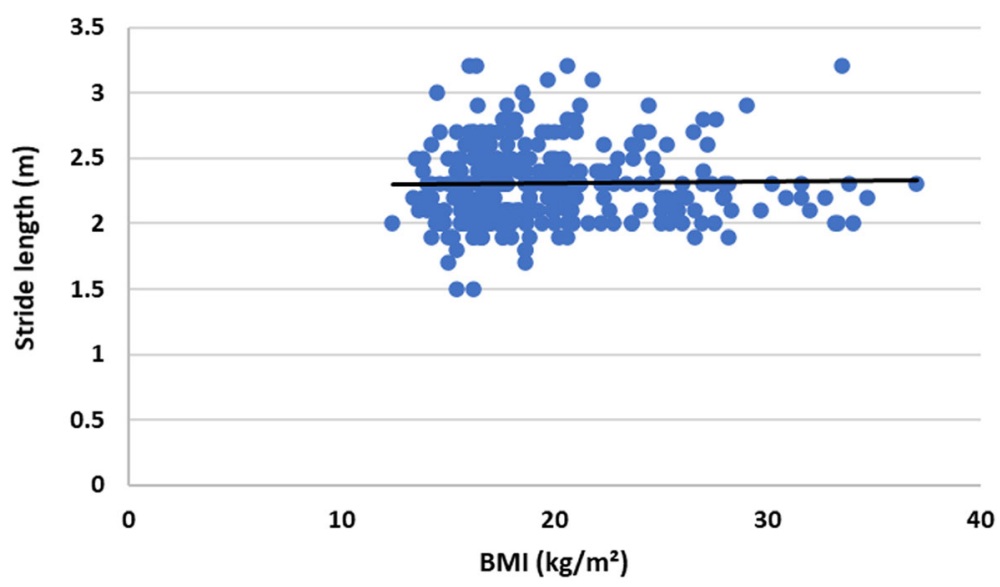

Fig. 2 Correlation between $\mathrm{BMI}$ and stride length of the children

\section{Conclusion}

According to our results, there is no significant relationship between BMI and the measured gait parameters (step length, stride length).

\section{Abbreviations}

BMI: Body mass index; CDC: Centers for Diseases and Prevention Control; DXA: Dual energy X-ray absorptiometry; $\mathrm{m}^{2}$ : Squared meter; RAST: Run-based anaerobic sprint test

\section{Acknowledgements}

The authors would like to thank the parents of all children participated in this study and school manager.

\section{Authors' contributions}

MR prepared the content of this manuscript and shared the assessment procedure. MS performed data analysis and interpretation. All authors read and approved the manuscript.

\section{Funding}

The authors confirm that this study received no financial support.

\section{Availability of data and materials}

The datasets used and/or analyzed during the current study are available from the corresponding author on reasonable request.

\section{Declarations}

\section{Ethics approval and consent to participate}

This study was approved by the Ethical Committee of the Faculty of Physical Therapy, Cairo University, Egypt (No.: P.T.REC/012/002621), and was performed in accordance with the Declaration of Helsinki of 1964 and its later amendments. All parents of the participating children in this study were informed about the nature and purpose of this study. All parents signed a written consent form that allowed the children to participate.

\section{Consent for publication}

Not applicable

\section{Competing interests}

The authors declare that they have no competing interests.
Received: 10 March 2021 Accepted: 5 July 2021

Published online: 22 September 2021

\section{References}

1. Heymsfield SB, Peterson CM, Thomas DM, Heo M, Schuna JM. Why are there race/ethnic differences in adult body mass index-adiposity relationships? A quantitative critical review. Obes Rev. 2016;17(3):262-75.

2. Freedman DS, Horlick M, Berenson GS. A comparison of the Slaughter skinfold-thickness equations and BMI in predicting body fatness and cardiovascular disease risk factor levels in children. Am J Clin Nutr. 2013; 98(6):1417-24

3. Wohlfahrt-Veje C, Tinggaard J, Winther K, Mouritsen A, Hagen CP, et al. Body fat throughout childhood in 2647 healthy Danish children: Agreement of BMI, waist circumference, skinfolds with dual X-ray absorptiometry. Eur J Clin Nutr. 2014:68(6):664-70.

4. Reddon H, Meyre D, Cairney J. Physical activity and global self-worth in a longitudinal study of children. Med Sci Sports Exerc. 2017:49(8):1606-13.

5. Wang Y, Lobstein T. Worldwide trends in childhood overweight and obesity. Int J Pediatr Obes. 2006;1(1):11-25.

6. Beydoun MA, Kuczmarski MT, Wang Y, Mason MA, Evans MK, Zonderman AB. Receiver-operating characteristics of adiposity for metabolic syndrome: The Healthy Aging in Neighborhoods of Diversity across the Life Span (HANDLS) study. Public Health Nutr. 2011;14(1):77-92.

7. Klein D, Sesselberg TS, Johnson MS, O'Connor KG, Cook S, et al. Adoption of body mass index guidelines for screening and counseling in pediatric practice. Pediatrics. 2010;125(2):265-72.

8. Shultz S. Examination of musculoskeletal injuries. 2nd ed. North Carolina: Human Kinetics; 2005.

9. Goodway J, Ozmun J, Gallahue D. Understanding motor development: Infants, children, adolescents, adults Learning: McGraw-Hill; 2011.

10. Breiman L. Classification and regression trees: Routledge; 2017.

11. Lacquaniti F, Ivanenko YP, Zago M. Development of human locomotion. Curr Opin Neurobiol. 2012;22(5):822-8.

12. Burden A. How should we normalize electromyograms obtained from healthy participants? What we have learned from over 25 years of research. J Electromyogr Kinesiol. 2010;20(6):1023-35.

13. Loudon J, Swift M, Bell S. The clinical orthopedic assessment guide. J Hum Kinet. 2008.

14. Pathare N, Haskvitz EM, Selleck M. Comparison of measures of physical performance among young children who are healthy weight, overweight, or obese. Pediatr Phys Ther. 2013;25(3):291-6.

15. Cimolin V, Galli M, Vismara L, Albertini G, Sartorio A, Capodaglio P. Gait pattern in lean and obese adolescents. Int J Rehabil Res. 2015;38(1):40-8

16. Cimolin V, Cau N, Sartorio A, Capodaglio P, Galli M. Symmetry of gait in underweight, normal and overweight children and adolescents. Sensors. 2019:19(9):2054

17. Rosso V, Agostini V, Takeda R, Tadano S, Gastaldi L. Influence of BMI on gait characteristics of young adults: 3D evaluation using inertial sensors. Sensors. 2019;19(19):4221. 
18. Rezaei $M$, Najafian R, Mazandarani E. The kinematics gait pattern analysis of thin, normal and obese children. Journal of Sport Biomechanics. 2018;4(2): 49-57.

19. Milanese C, Bartolomeo O, Bertucco M, Verlato G, Zancanaro C. Anthropometry and motor fitness in children aged 6-12 years. J Hum Sport and exercise. 2010

20. Hung YC, Gill SV, Meredith GS. Influence of dual-task constraints on wholebody organization during walking in children who are overweight and obese. Am J Phys Med Rehabil. 2013;92(6):461-71.

21. Heneidy WE. Gait parameters in children with different weight abnormalities. CU Theses; 2012.

22. Dufek JS, Currie RL, Gouws PL, Candela L, Gutierrez AP, et al. Effects of overweight and obesity on walking characteristics in adolescents. Hum Mov Sci. 2012;31(4):897-906.

23. Gouws P-L. Effects of obesity on the biomechanics of children's gait at different speeds; 2010.

24. Roles K. Differences in Running Mechanics Between Overweight/Obese and Healthy Weight Children; 2016.

\section{Publisher's Note}

Springer Nature remains neutral with regard to jurisdictional claims in published maps and institutional affiliations.

\section{Submit your manuscript to a SpringerOpen ${ }^{\circ}$ journal and benefit from:}

- Convenient online submission

- Rigorous peer review

- Open access: articles freely available online

- High visibility within the field

- Retaining the copyright to your article

Submit your next manuscript at $\boldsymbol{\nabla}$ springeropen.com 